\title{
Induced cytokine network during experimental African trypanosomiasis
}

This article was published in the following Dove Press journal:

International Journal of Interferon, Cytokine and Mediator Research

5 December 2011

Number of times this article has been viewed

\section{Karina Pires de Sousa \\ Jorge M Atouguia \\ Marcelo Sousa Silva}

Unidade de Ensino e Investigação de Clínica Tropical, Centro de Malária e Outras Doenças Tropicais (CMDT), Instituto de Higiene e Medicina Tropical, Universidade Nova de Lisboa, Lisboa, Portugal
Correspondence: Marcelo Sousa Silva Instituto de Higiene e Medicina Tropical, IHMT, Av. da Junqueira, 100. I349-008 Lisboa, Portugal Tel +35 I 213652600

Fax +35I 213622458

Email mssilva@ihmt.unl.pt

\begin{abstract}
African trypanosomiasis (AT) is caused by extracellular hemoflagellates of the genus Trypanosoma and develops into a fatal disease for man and animals. The immune response and pathogenesis associated with the illness are complex and still poorly understood. However, they seem to be characterized by extensive changes in lymphoid tissues of the infected host, involving a complex network of interactions between cells and their products, which are controlled by specific parasite molecules. Various studies suggest that cytokine responses influence the outcome of AT; however, the precise role of individual cytokines remains unclear and may depend on the animal model and the parasite strain. This review focuses on how the parasite manipulates the immunoregulatory mechanisms in the generation of host cytokine response and their relationship with macrophages activation in the experimental model of the African sleeping sickness.
\end{abstract}

Keywords: Trypanosoma brucei, sleeping sickness, T helper cells

\section{Introduction}

The African parasites of the species Trypanosoma brucei are extracellular hemoflagellate protozoa transmitted by the bite of the tsetse fly, capable of infecting both humans and livestock. The subspecies T. $b$. rhodesiense and T. $b$. gambiense are the causative agents of the acute and chronic forms of the disease commonly known as sleeping sickness (in humans). T. b. brucei is one the chief pathogens infecting livestock, ${ }^{1}$ producing a disease known as nagana. Annually, about 45,000 new cases of human African trypanosomiasis (AT) are reported; however, it is estimated that there are about 500,000 people infected with this disease, and moreover, that more than 60 million people are continuously exposed to the danger caused by $T$. $b$. rhodesiense and T. $b$. Gambiense. ${ }^{2}$ The disease is characterized by an early hemolymphatic stage followed by a meningo-encephalitic stage, in which trypanosomes and/or increased numbers of leukocytes are found in the cerebrospinal fluid. ${ }^{3}$

African trypanosomes can powerfully modulate their host immune system. These parasites evade the immune responses mainly by modification of their variant surface glycoproteins (VSGs) by means of a complex process referred to as antigenic variation. ${ }^{4}$ To complete their life cycle, trypanosomes require an essential developmental step in a mammalian host, consequently having to cope with the constant assail of the host immune system, while creating a state of equilibrated growth regulation that ensures optimal survival and effective transmission. ${ }^{5}$

The molecular mechanisms that trypanosomes employ in order to survive and proliferate in the bloodstream of their mammalian hosts have been objects of 
investigation for most of the past century, but still the immune responses and pathogenesis processes that occur in a mammalian ailing with AT are poorly understood. It is known, however, that different strains of mice display different degrees of susceptibility to the disease, ${ }^{6}$ and this might be of use in the study of the mechanisms underlying resistance to African trypanosomes. Infecting mice with these parasites results in the proliferation of $\mathrm{T}$ and $\mathrm{B}$ cells, and also in the activation of macrophages in the spleen and bone marrow, followed by the inability of either $\mathrm{T}$ or $\mathrm{B}$ cells to respond to mitogens or specific antigens ${ }^{7}$ and also the destruction of lymphoid structures. Therefore, it is legitimate to claim that infection with African trypanosomes induces multiple disorders in the immune system. Also, the intricate cytokine network that controls the host cell-mediated immune response in experimental AT comes as a difficulty to the investigation of the mechanisms underlying regulation of the infection, due to the complex interactions between the host immune response and the parasite survival strategies; hence, it is with great difficulty that the mechanisms that govern resistance and susceptibility to the disease are being characterized.

While some mouse strains are more resistant to the infection by $T$. brucei (like C57BL/6) and survive longer (more than 30 days after the infection), suffering in the end from severe pathology, other strains (like BALB/c) are more susceptible and succumb rapidly to the infection (usually in less than or around 20 days). ${ }^{8}$ Therefore, the terminology "resistant"/"susceptible" will be used bearing in mind that, in fact, there are no actual resistant models for $T$. brucei infections, only relatively resistant and highly susceptible animals. Studies aiming to explain the susceptibility of the different mouse strains to AT are so far inconclusive for the T. brucei model (as opposed to studies using T. congolense, for example). ${ }^{8,9}$

Several studies report the influence of the cytokine response in the parasite's development; however, the precise role of each individual cytokine remains unclear and may depend on the animal model, the parasite strain, or both. In this paper, the focus is on the network of cytokine responses and its relation with macrophages and other cell types in the experimental animal model of infection with T. brucei.

\section{Consequences of macrophage activation in AT}

The involvement of macrophages in experimental AT has been comprehensively established in several experiments, ${ }^{10-12}$ with different studies demonstrating that (1) macrophage activation can be detected within a few days of infection with African trypanosomes, ${ }^{13,14}$ (2) there is a severe increase in activated macrophages in the tissues of trypanosomeinfected animals, ${ }^{15-18}$ and (3) lymphoid organs of infected mice become markedly enlarged during infection due to a disproportionate increase in macrophages within these tissues. ${ }^{19}$ Also, mice infected with African trypanosomes show increased production of interleukin (IL)-12, tumor necrosis factor (TNF)- $\alpha$, nitric oxide (NO), superoxide anion, and derived hydrogen peroxide, produced as a result of the oxidative burst. ${ }^{15-17}$ This macrophage activation has been well documented in previous studies, but there are also data implicating macrophages in the immune dysfunction and downregulation of adaptive immunity characteristic of AT. ${ }^{18-20}$ In fact, one of the remarkable features of the trypanosome infections is the strong generalized suppression of the immune responses, which have been reported to affect a large variety of both the humoral and the cellular immune functions. ${ }^{21}$

Besides the roles of classically activated macrophages (M1) in parasite control and pathogeneses, and of alternatively activated macrophages (M2) in anti-inflammatory mechanisms, both cell types seem to participate in the immunosuppression typical of AT. ${ }^{22}$ Also, the suppressive activities of M1 and M2 cells might contribute to the inability of infected hosts to mount a long-lived memory response. ${ }^{22}$

Interestingly, Harris et $\mathrm{al}^{23}$ have demonstrated that deoxyribonucleic acid (DNA) from $T$. $b$. rhodesiense is released during infection and is capable of modulating macrophage activity in vitro. Moreover, this study has shown that the appearance of DNA in the blood and tissues of infected mice may play a critical role in the response of macrophages to the parasite within the first several days following infection. This early response may be a critical component of relative resistance in AT.

\section{TNF- $\alpha$}

The role of TNF- $\alpha$ in trypanosome-associated immunopathology during infection has been demonstrated in a number of studies documenting, for instance, (1) the enhanced expression of TNF- $\alpha$ mRNA in the brain of $T$. brucei-infected mice, ${ }^{24}(2)$ the association between TNF- $\alpha$ production by monocytes and the severity of disease-associated anemia in trypanosome-infected cattle, ${ }^{21}$ (3) the correlation between serum TNF- $\alpha$ levels and the severity of neuropathological symptoms in human sleeping sickness, ${ }^{25}$ and (4) the involvement of TNF- $\alpha$ in trypanosome-elicited immunosuppression. ${ }^{26}$ Taken together, the accumulated knowledge about trypanosome-elicited production of TNF- $\alpha$ indicates that this cytokine exerts dual 
effects during trypanosome infections, influencing both the parasite and the host. ${ }^{5}$

Controversially, TNF- $\alpha$ has been reported protective to the host, in cases in which it exhibits static and lytic effects on the T. brucei parasites. ${ }^{5,27,28}$ In accordance, TNF-deficient mice showed increased parasitemia in both T. b. brucei and T. b. rhodesiense infection. ${ }^{5,29}$ However, the direct effector function of TNF- $\alpha$ on trypanosomes is only confirmed in a limited number of $T$. brucei strains and is not a general operating mechanism. ${ }^{30}$

\section{NO}

Research on the role of NO in AT has also generated interesting, and contradictory, results. Therefore, the exact role for this molecule is yet to be clearly understood. Paradoxical results have been reported, and different groups describe conflicting outcomes, even when taking into account that different clones of the parasite may produce different results and should be interpreted accordingly.

For instance, it has been demonstrated by Sternberg and McGuigan $^{31}$ that both peritoneal and splenic cell cultures from infected mice release nitrite and that this release correlates with suppressed splenic T-cell proliferative responses to concanavalin A (ConA). The same work showed that, in T. brucei infection, the activation of macrophages to produce NO leads to impaired lymphocyte responses and immunosuppression. Accordingly, it has also been shown that the chemical inhibition of NO synthase (NOS) produces an improved control of the first wave of parasitemia and a restoration of lymphoproliferative responses. ${ }^{32}$

In contrast, Mabbott et al, ${ }^{33}$ working with a different strain of T. brucei, presented evidence for an NO-dependent inhibition of the parasite growth when its bloodstream form was added to peritoneal macrophages activated in vitro. Furthermore, this work suggested that $T$. brucei is not susceptible to NO-mediated killing in vivo. On the other hand, the T. brucei clone, LouTat1, is known to be sensitive to NO and to die rapidly in culture in its presence, while addition of $\mathrm{N}^{\mathrm{G}}$-monomethyl L-arginine (L-NMMA), an inhibitor of the L-arginine-NO metabolic pathway, is able to inhibit NO release and revoke its cytotoxic effect on trypanosomes. ${ }^{20}$ A different investigation by Vincendeau et $\mathrm{al}^{34}$ showed that the trypanostatic activity of activated macrophages is inhibited by the addition of L-NMMA, indicating a role for $\mathrm{NO}$ as the effector molecule. The same work showed that, contrary to trypanosomes treated with $\mathrm{N}_{2}$ gas, trypanosomes treated with NO gas do not proliferate in vitro on normal macrophages. Compared with mice infected with control parasites, mice infected with NO-treated parasites have decreased parasitemia in the first days post-infection and have a prolonged survival.

Studies using knockout mice have also been utilized in the attempt to clarify the role of NO in T. brucei infections; induced NOS (iNOS) $)^{-/}$mice behaved similarly to fully immune-competent control mice. ${ }^{35}$ However, treatment studies using a specific NOS inhibitor $\left(\mathrm{N}^{\mathrm{G}}\right.$-nitro-L-arginine methyl ester), in addition to one knockout-mice study, highlighted the role of NO in T. brucei-induced immunosuppression and anemia. ${ }^{36}$

Interestingly, it has been shown ${ }^{37}$ that $\mathrm{NO}$ is involved in the inhibition of ConA-induced T-cell proliferation in the spleen and in the lymph nodes during the early (in particular before the first peak of parasitemia) but not the late stage of infection and, in addition, that $T$. bruce $i$ elicits different suppressive mechanisms in these lymphoid compartments that are sequentially activated in function of the stage of infection.

More particularly, in the case of the human sleepingsickness disease, a concise report ${ }^{38}$ suggests that the duration of early-stage infection after a fly bite is critical in determining NO responses and that NO synthesis is strongly downregulated at a point within the first 40 days of infection with $T$. brucei. The same work has shown that a decline in NOS activity as infection progresses is consistent with significantly elevated interferon (IFN)- $\gamma$ levels in the early stage of infection, with a subsequent decline in late-stage infection. The decline in the expression of this T helper (Th)-1 cytokine is not accompanied by any increase in Th-2 cytokine levels in the plasma of sleeping-sickness patients, as evidenced by the low level of IL-4 at all stages of infection. ${ }^{39}$ Interestingly, there seems to be no increase in the nitrate levels in the central nervous system of the human patients in this study, during infection.

\section{IFN- $\gamma$}

It has been shown that experimental infection with $T$. brucei infection elicits different tissue- and infection stage-dependent suppressive mechanisms. According to several results described by Darji et al, ${ }^{26,40}$ IFN- $\gamma$ appears to act as a key molecule in the T. brucei-elicited suppression of T-cell proliferative responses, since addition of anti-IFN- $\gamma$ antibodies to co-cultures of suppressive cells and mitogen-stimulated lymph node cells restores T-cell proliferation. ${ }^{26}$ Also, it has been found that: (1) $\mathrm{CD}^{+} \mathrm{T}$ cells are responsible for this IFN- $\gamma$ hyperproduction, ${ }^{41}$ which is in accordance with reports showing that lymph node cells from T. brucei-infected mice 
are hyperresponsive for IFN- $\gamma$ production despite impaired T-cell mitogenesis; ${ }^{2,40}$ (2) T. brucei-mediated hyperproduction of IFN- $\gamma$ is tissue- and infection-stage dependent; ${ }^{15}$ and (3) there is increased IFN- $\gamma$ production during AT. ${ }^{42}$

In fact, it has been suggested ${ }^{32}$ that $T$. bruce $i$-mediated induction of IFN- $\gamma$ production may represent the first event in the pathway of suppression, since very large numbers of IFN- $\gamma$-producing $\mathrm{CD} 8^{+} \mathrm{T}$ cells can be detected in infected rats as early as 12 hours post-infection. ${ }^{41}$ This fast IFN- $\gamma$ production in vivo is most probably induced directly by the parasite, since T. brucei-released factors are described as capable of triggering in a non-antigen-specific way a rapid release of IFN- $\gamma$ by $\mathrm{CD}^{+}$cells. $^{40,43}$

IFN- $\gamma$-mediated macrophage activation also results in simultaneous increased production of TNF- $\alpha$ and NO, which are respectively trypanolytic and trypanostatic for T. brucei. ${ }^{27,28,44}$ Moreover, NO generated by IFN- $\gamma$-dependent macrophages contributes to the inhibition of T-cell proliferation. ${ }^{37}$ Interestingly, addition of exogenous IFN- $\gamma$ to cultures containing lymph node cells from infected IFN- $\gamma$ knockout mice does not impair proliferation despite NO production in such cultures. Thus, during late-stage infection, an IFN- $\gamma$-independent suppressive mechanism is elicited in the spleen, whereas in the lymph nodes, IFN- $\gamma$ is required yet is not sufficient to inhibit T-cell proliferation. ${ }^{37}$

Furthermore, it has been demonstrated that high levels of IFN- $\gamma$ are associated with enhanced susceptibility to $T$. brucei infection (and consequentially to the immunosuppression of T cells described before) and the production of iNOS in macrophages isolated from infected mice. ${ }^{35}$ However, it has also been shown that IFN- $\gamma$ knockout mice are susceptible to infection by T. brucei. ${ }^{45,46}$ Therefore, even though the experimental data suggest that IFN- $\gamma$ plays a central role in the pathway of immunosuppression, this cytokine is not probably the sole effector of suppression; it seems more likely that IFN- $\gamma$ is required yet not sufficient to inhibit mitogeninduced T-cell proliferation.

Finally, IFN- $\gamma$ also induces the production of a mitogenactivated protein kinase that contributes to the proliferation of trypanosomes in the bloodstream. ${ }^{47}$ This binding, activation, and secretion of IFN- $\gamma$ by $\mathrm{CD}^{+} \mathrm{T}$ cells might then stimulate the exponential growth of the bloodstream forms of a pleomorphic T. brucei population, suggesting an important function for $\mathrm{CD} 8$ molecules and $\mathrm{CD}^{+} \mathrm{T}$ cells during the course of experimental AT. The increased production of IFN- $\gamma$ rules the macrophage activation that results in the secretion of TNF- $\alpha$ and NO, which are both important molecules for parasite control.

\section{Prostaglandins (PGs)}

The generation of PGs by macrophages is also implicated in the suppression mechanism of lymphocyte response during T. brucei infection. ${ }^{40}$ PGs are described as responsible for inhibiting IL-2 production; furthermore, $\mathrm{CD}^{+}$and $\mathrm{CD}^{+}$ $\mathrm{T}$ cells are unable to express IL-2 receptor in the presence of indomethacin (a PG inhibitor), suggesting a PG-independent mechanism. ${ }^{48}$ Experiments to address the role of NO or PG in T-cell suppression suggest that in the early phase of infection, simultaneous inhibition of both NO and PG synthesis with specific inhibitors reverses the suppressor cell activity; however, such treatment does not affect the late stage of the disease, ${ }^{49}$ from which it is reasonable to conclude that NO and PG are partially responsible for the suppressor-cell effect in AT.

It has also been suggested that resistance to T. brucei infection requires a temporal activation of pro- and antiinflammatory mechanisms. ${ }^{12}$ MacLean et $\mathrm{al}^{38}$ have demonstrated a strong anti-inflammatory cytokine response in human AT. Several papers indicate that the interaction of African trypanosomes with macrophages, other trypanosomes, or their products, results in the secretion of pro-inflammatory molecules such as TNF- $\alpha$, IL-1, IL-6, and NO by macrophages. ${ }^{5,13,16}$ These molecules are able to activate lymphocytes, mainly $\mathrm{CD}^{+} \mathrm{T}$ cells, to produce IFN- $\gamma$. An interesting observation is that bone marrow-derived macrophages (BMDMs) from C57BL/6 mice (partially resistant to AT) produce TNF- $\alpha$ and IL-12, while BMDM from $\mathrm{Balb} / \mathrm{c}$ mice (susceptible to AT) produce IL-6 and IL-10. ${ }^{50}$

\section{The role of VSGs in the development of cytokine responses}

Trypanosomes subsist extracellularly in the blood and tissues and must therefore circumvent the host immune system. This deed is mainly achieved by means of an amazing adaptive mechanism: antigenic variation. The bloodstream form of trypanosomes is entirely covered with a monolayer made of $10^{7}$ copies of the trypanosome's major surface antigen: the membrane form of the $\mathrm{VSG},{ }^{8}$ a highly variable molecule where the antigenicity is very high. ${ }^{2,51}$ The presence of the VSG coat creates a physical barrier that protects the parasite against the effector mechanisms of the immune system ${ }^{4,52}$ and, moreover, hampers immunization against the trypanosomes and leaves chemotherapy as the only disease-control method.

Expression of the VSG is essential in the antigenic variation process and eventually exhausts the host immune system in benefit of the parasite. ${ }^{2}$ This is a very interesting ability, and several researchers have based their works on 
the quest for finding invariable surface proteins that could contribute to the development of vaccine preparations or therapeutic targets, since the repertoire of genes coding for VSGs is very large, and vaccination against trypanosomiasis based on the variant antigens is believed to be impracticable. ${ }^{53}$ In fact, the trypanosome genome contains hundreds of VSG genes of which very few are fully functional (7\%), and the majority are full-length pseudogenes (with frame shifts and/ or in-frame stop codons), ${ }^{4,54}$ the current idea is that the actual functional VSG gene repertoire is small, and that the creation of mosaic VSGs via antigenic variation mechanisms offers the significant possibility of escaping the immune system, together with the active destruction of B-cell memory.

VSGs are anchored to the parasite membrane by a glycosylphosphatidylinositol (GPI) structure. These proteins have been associated with the development of a polarized Th-1 immune response in resistant mice infected with $\mathrm{AT}^{41}$ and more importantly, they have been reported as being able to directly activate macrophages, suggesting an interaction of host macrophages with this protein during parasite infection. The work described by Hertz et $\mathrm{al}^{35}$ was the first to demonstrate that the relative resistance of mice infected with AT could be associated with a strong Th-1 cell response to VSG antigens from T. brucei. The host resistance to the disease was associated with the presence of IFN- $\gamma$, with susceptible animals unable to elicit a compensatory Th- 2 cell response in the absence of Th-1 cell cytokine responses. Paulnock and Coller ${ }^{55}$ have shown that VSG glycoproteins released by trypanosomes bind to the macrophage membrane, inducing potent macrophage activation as a result of the interaction of the GPI membrane anchor with these cells. This suggests that the VSG molecules are highly immunogenic for all mouse strains upon immunization, even if the ability of animals to mount the VSG-specific B-cell response after infection differs noticeably, in accordance to the degree of susceptibility of a particular strain to the disease.

In the murine model, it has been shown that the VSGspecific cytokine responses associated with the resistance to AT are infection-stage dependent, with the type-I cytokine responses being critical during the early stage of infection, and the type-II cytokine responses more important during the late and chronic phases of the disease.

\section{Trypanosome-derived lymphocyte triggering factor (TLTF) and CD8 ${ }^{+}$ T-cell participation in AT}

The host-parasite interaction, in particular the bidirectional signaling between T. b. brucei and $\mathrm{CD}^{+} \mathrm{T}$ cells, involves reciprocal action of the parasite-derived TLTF, and lymphocyte-derived IFN- $\gamma,{ }^{56}$ which as discussed before, increases dramatically in the blood just a few hours after infection with the parasite.

The TLTF molecule is therefore a secreted component that binds to the $\mathrm{CD} 8$ molecule of $\mathrm{CD}^{+} \mathrm{T}$ cells and prompts them to produce IFN- $\gamma,{ }^{56,57}$ which in turn stimulates proliferation of T. b. brucei.$^{57}$ Secretion of TLTF is a constitutive, active, dose-response process. ${ }^{56}$

In accordance with these findings, it has been shown that animals depleted of $\mathrm{CD}^{+} \mathrm{T}$ cells experience a decrease in the IFN- $\gamma$ blood levels. These results, however, contrast with the fact that depletion of $\mathrm{CD}^{+} \mathrm{T}$ cells induces the same level of IFN- $\gamma$ as in wild-type animals of the same strain, infected with the same parasite. ${ }^{23}$ According to Hamadien et al, ${ }^{58}$ wild-type mice show high parasitemia accompanied by high TLTF levels and low anti-TLTF antibodies at day 3 post-infection, and low TLTF levels measured together with increased anti-TLTF antibodies at day 21 post-infection. In the same experiment, knockout IFN- $\gamma$ mice exhibit very low parasitemia, TLTF and anti-TLTF antibody levels, with the overall data demonstrating a role for IFN- $\gamma$ in the generation of neutralizing antibodies to TLTF. ${ }^{58}$

\section{Th-2 cytokine activation in AT}

The involvement of Th-2 cytokines in the course of AT in mice is attributed to an exaggerated control of Th-1 cytokine activation. Aiming to prevent the excessive production of IFN- $\gamma$ (a Th-1-type cytokine), IL-10 may be responsible for maintaining the balance between pathogenic and protective immune responses during the infection, ${ }^{32}$ suggesting a crucial role of IL-10 cytokine (a Th-2-type cytokine) in the enhanced survival of mice and downregulation of Th-1 responses and early inflammatory immune responses.

Experiments with mice deficient in IL-4 have shown that the parasitemia is unaltered when compared with wildtype control mice. In contrast, when IL-10-deficient mice are infected with $T$. brucei parasites, the first peak of parasitemia is appropriately controlled, but the mice succumb to infection-associated pathologies within days of parasite elimination. ${ }^{8,46,59}$ It has furthermore been demonstrated that in both IL-4- and IL-10-deficient C57BL/6 mice (relatively resistant), infection with $T$. brucei causes a significantly shorter survival period than in infected wild-type mice, indicating that IL-10 might be crucial for enhanced survival of mice infected with T. brucei. ${ }^{46}$

On the contrary, Inoue et $\mathrm{al}^{47}$ suggest that $\mathrm{CD}^{+} \mathrm{T}$ cells may have power over the parasitemia in T. brucei infection 
via the IL-4 pathway. According to their results, both IL-4 and IFN- $\gamma$ are detected in T. b. gambiense-infected mice. Serum concentrations of these cytokines decrease in $\mathrm{CD} 4^{+} \mathrm{T}$-celldepleted mice. It has been shown that $\mathrm{CD} 4^{+} \mathrm{T}$-cell-regulated IL-4 production is crucial for controlling T. b. gambiense infections in mice, ${ }^{47}$ and on the contrary, that IL-4 knockout mice do not show any alteration in the parasite control. ${ }^{45}$ However, Namangala et a ${ }^{60}$ showed that during the chronic stage of infection, Th-2 cytokine production as well as an immunoglobulin G1 antibody response to the trypanosome antigens is linked to the longer survival of the host in the T. bruce i infection model. Moreover, in the case of the human disease, the levels of IL-10 and IL- 6 in the brain have been shown to be associated with the protection from neuroinflammatory pathology. ${ }^{61}$

It is generally known that classically activated macrophages are associated with a Th-1 immune response and inhibit T-cell proliferation via the production of $\mathrm{PGs}$, reactive oxygen intermediates, and NO. In contrast, alternatively activated macrophages develop in the context of a Th-2 immune setting and make use of their suppressive potential by secreting IL-10. ${ }^{60}$ Importantly, the two macrophage subsets are antagonistically regulated: alternative macrophages are induced by IL-4 and inhibited by IFN- $\gamma$, whereas classical macrophages are induced by IFN- $\gamma$ and inhibited by IL- $4 .{ }^{60}$ Accordingly, Namangala et $\mathrm{al}^{62}$ have shown that $T$. b. brucei might educe classically activated suppressive macrophages. Although this work does not agree with the idea that the Th-1 immune response is protective during $\mathrm{AT},{ }^{45,50,53}$ one cannot exclude that a switch to a Th-2 cytokine response during the late/chronic phase of infection may be more beneficial to the host, leading to a persistent but less pathologic infection, ${ }^{53}$ since it would reflect the capacity of the host to control the parasite first and the pathology later. ${ }^{3}$

\section{Conclusion}

Resistance to $T$. brucei infection requires a temporal activation of pro- and anti-inflammatory mechanisms. Characterization of the mechanisms that preside over these processes could suggest ways of intervention that might lead to ideas about disease control, sterile immunity, or vaccination. The precise role of each individual cytokine in the phenomena of trypanotolerance remains unclear, since animal models have provided conflicting evidence regarding the immunologic factors that influence the magnitude of resistance to AT. Different works have, so far, demonstrated conflicting roles for cytokines in the immunopathology of different experimental models of AT, making it difficult to foretell whether cytokines play a protective role by contributing to immune eradication of the microbial attack or are causing inflammatory damage and disease.

In the future, full advantage should be taken of the different genetic backgrounds of the different strains of mice in studies using gene deletion, monoclonal antibody, or cytokine treatment to solve the many remaining questions that surround trypanosomiasis pathogenesis and the development of new treatment modalities. Moreover, since the major pathological feature of AT is neurological damage involving type-1-related inflammatory mediators, understanding the function of classically and alternatively activated macrophages in the murine models could be useful for future intervention strategies. Also, it is clear that the role of macrophage activation and other elements of the innate immune system in regulating host resistance is complex and remains to be fully elucidated.

\section{Acknowledgments}

This work is supported by grants from Fundação para a Ciência e Tecnologia (FCT: PTDC/CVT/3624/2006 and PTDC/CVT/102486/2008) and Fundação Calouste Gulbenkian (Proc105228). MS Silva would like to thank FCT for a post-doctoral fellowship (SFRH/BPD/26491/2006).

\section{Disclosure}

The authors declare to have no conflict of interests (personal or financial) in the publication of this paper.

\section{References}

1. Taylor K, Authié EML. Pathogenesis of animal trypanosomiasis. In: Maudlin I, Holmes PH, Miles MA, editors. The Trypanosomiasis. Wallingford: CAB Publishing; 2004:331-334.

2. Baral TN. Immunobiology of African trypanosomes: need of alternative interventions. J Biom Biotechnol. 2010; Article ID: 389153.

3. Amin DN, Rottenberg ME, Thomsen AR, et al. Expression and role of CXCL10 during the encephalitic stage of experimental and clinical African trypanosomiasis. J Infect Dis. 2009;200:1556-1565.

4. Cross GA. Cellular and genetic aspects on antigenic variation in trypanosomes. Ann Rev Immunol. 1990;8:83-110.

5. Magez S, Radwanska M, Beschin A, Sekikawa K, De Baetselier P. Tumor necrosis factor alpha is a key mediator in the regulation of experimental Trypanosoma brucei infections. Infect Immun. 1999;67(6):3128-3132.

6. Greenblatt HC, Diggs CL, Rosenstreich DL. Trypanosoma rhodesiense: analysis of the genetic control of resistance among mice. Infect Immun. 1984;44(1):107-111.

7. Mayor-Withey KS, Clayton CE, Roelants GE, Askonas BA. Trypanosomiasis leads to extensive proliferation of B and T and null cells in spleen and bone marrow. Clin Exp Immunol. 1978;34(3):359-363.

8. Antoine-Moussiaux N, Magez S, Desmecht D. Contributions of experimental mouse models to the understanding of African trypanosomiasis. Trend Parasitol. 2008;24(9):411-418.

9. Magez S, Caljon G. Mouse models for pathogenic African trypanosomes: unravelling the immunology of host-parasite-vector interactions. Parasite Immunol. 2011;33:423-429. 
10. Grosskinsky CM, Askonas BA. Macrophages as primary target cells and mediators of immune dysfunction in African trypanosomes. Infect Immun. 1981;33(1):149-155.

11. Fierer J, Askonas BA. Trypanosoma brucei infection stimulates receptor-mediated phagocytosis by murine peritoneal macrophages. Infect Immun. 1982;37(3):1282-1284.

12. Namangala B, De Baetselier P, Noel W, Brys L, Beschin A. Alternative versus classical macrophage activation during experimental African trypanosomosis. J Leuk Biol. 2001;69(3):387-396.

13. Scheleifer KW, Filutowicz H, Schopf LR, Mansfield JM. Characterization of $\mathrm{T}$ helper cell responses to the trypanosome variant surface glycoprotein. J Immunol. 1993;150(7):2910-2919.

14. Wellhausen SR, Mansfield JM. Lymphocyte function in experimental African trypanosomiasis. II. Splenic suppressor cell activity. J Immunol. 1979;22:818-824.

15. Grosskinsky CM, Ezekowitz RA, Berton G, Gordon S, Askonas BA. Macrophages activation in murine African trypanosomiasis. Infect Immunol. 1983;39(3):1080-1086.

16. Mabbott N, Sternberg J. Bone marrow nitric oxide production and development of anemia in Trypanosoma brucei-infected mice. Infect Immunol. 1995;63(4):1563-1566.

17. Segal AW, Abo B. The biochemical basis of the NADPH oxidase of phagocytes. Trend Biochem Sci. 1993;18(2):43-47.

18. Nishimura K, Nakaya H, Nakagawa H, Matsuo S, Ohnishi Y, Yamasaki S. Differential effects of Trypanosoma brucei gambiense and Trypanosoma brucei brucei on rat macrophages. J Parasitol. 2011;97(1):48-54.

19. Lopez R, Demick KP, Mansfield JM, Paulnock DM. Type I IFNs play a role in early resistance, but subsequent susceptibility, to the African trypanosomes. J Immunol. 2008;181:4908-4917.

20. Schleifer KW, Mansfield JM. Suppressor macrophages in African trypanosomiasis inhibit $\mathrm{T}$ cell proliferative responses by nitric oxide and prostaglandins. J Immunol. 1993;151(10):5492-5503.

21. Sileghem M, Flynn JN, Darji A, De Baetselier P, Naessens J. African trypanosomiasis. In: Kierszenbaum F, editor. Parasite Infections and the Immune System. San Diego: Academic Press; 1994:1-51.

22. Gómez-Rodríguez J, Stijlemans B, De Muylder G, et al. Identification of a parasitic immunomodulatory protein triggering the development of suppressive M1 macrophages during African trypanosomiasis. $J$ Infect Dis. 2009;200:1849-1860.

23. Harris TH, Cooney NM, Mansfield JM, Paulnock DM. Signal transduction, gene transcription, and cytokine production triggered in macrophages by exposure to trypanosome DNA. Infect Immun. 2006;74(8):4530-4537.

24. Hunter CA, Gow JW, Kennedy PGE, Jennings FW, Murray M. Immunopathology of experimental African sleeping sickness: detection of cytokine mRNA in the brains of Trypanosoma brucei brucei-infected mice. Infect Immun. 1991;59(12):4636-4640.

25. Okomo-Assoumou MC, Daulouede S, Lemesre JL, N'Zila-Mouanda A, Vincendeau P. Correlation of high serum levels of tumor necrosis factor-alpha with disease severity in human African trypanosomiasis. Am J Trop Med Hyg. 1995;53(5):539-543.

26. Darji A, Beschin A, Sileghem M, Heremans H, Brys L, De Baetselier P. In vitro simulation of immunosuppression caused by Trypanosoma brucei: active involvement of gamma interferon and tumor necrosis factor in the pathway of suppression. Infect Immun. 1996;64(6):1937-1943.

27. Lucas R, Magez S, Songa B, Darji A, Hamers R, De Baetselier P. A role for TNF during African trypanosomiasis: involvement in parasite control, immunosuppression and pathology. Res Immunol. 1993;144(5):370-376.

28. Magez S, Geusken M, Beschin A, et al. Specific uptake of tumor necrosis factor-alpha is involved in growth control of Trypanosoma brucei. J Cell Biol. 1997;137(3):715-727.

29. Naessens J, Kitani H, Nakamura Y, Yagi Y, Sekikawa K, Iraqi F. TNF alpha mediates the development of anaemia in a murine Trypanosoma brucei rhodesiense infection, but not the anaemia associated with a murine Trypanosoma congolense infection. Clin Exp Immunol. 2005;139:405-410.
30. Kitani H, Black SJ, Nakamura Y, et al. Recombinant tumor necrosis factor alpha does not inhibit the growth of African trypanosomes in axenic cultures. Infect Immun. 2002;70(4):2210-2214.

31. Sternberg J, McGuigan F. Nitric oxide mediates suppression of T cell responses in murine Trypanosoma brucei infection. Eur J Immunol. 1992;22(10):2741-2744.

32. Sternberg J, Mabbott N, Sutherland I, Liew FY. Inhibition of nitric oxide synthesis leads to reduced parasitemia in murine Trypanosoma brucei infection. Infect Immun. 1994;62:2135-2137.

33. Mabbott NA, Sutheland IA, Sternberg JM. Trypanosoma brucei is protected from the cytostatic effect of nitric oxide under in vivo conditions. Parasitol Res. 1994;80(8):687-690.

34. Vincendeau P, Daulouede S, Veyret B, Darde ML, Bouteille B, Lemesre JL. Nitric oxide-mediated cytostatic activity on Trypanosoma brucei gambiense and Trypanosoma brucei brucei. Exp Parasitol. 1992;75(3):353-360.

35. Hertz CJ, Hanna F, Mansfield JM. Resistance to the African trypanosomes is IFN-gamma dependent. J Immunol. 1998;161:6775-6783.

36. Millar AE, Sternberg J, McSharry C, Wei XQ, Liew FY, Turner CMR. T-cell responses during Trypanosoma brucei infections in mice deficient in inducible nitric oxide synthase. Infect Immun. 1999;67:3334-3338.

37. Beschin A, Brys L, Magez S, Radwanska M, De Baetselier P. Trypanosoma brucei infection elicits nitric oxide-dependent and nitric oxide-independent suppressive mechanisms. J Leukoc Biol. 1998;63(4):429-439.

38. MacLean L, Odiit M, Jeremy M. Sternberg. Nitric oxide and cytokine synthesis in human African trypanosomiasis. J Infect Dis. 2001;184:1086-1090.

39. Vincendeau P, Daulouede S. Macrophage cytostatic effect on Trypanosoma musculi involves an L-arginine-dependent mechanism. J Immunol. 1991;146(12):4338-4343.

40. Darji A, Sileghem H, Heremans L, Brys L, De Baetselier P. Inhibition of T-cell responsiveness during experimental infections with Trypanosoma brucei: active involvement of endogenous gamma interferon. Infect Immun. 1993;61(7):3098-3102.

41. Bakhiet M, Olsson T, van der Meide PH, Kristensson K. Depletion of CD8+ T cells suppresses growth of Trypanosoma brucei brucei and interferon-gamma production in infected rats. Clin Exp Immunol. 1990;81(2):195-199.

42. Bakhiet M, Olsson T, Mhlanga J, et al. Human and rodent interferongamma as a growth factor for Trypanosoma brucei. Eur J Immunol. 1996;26:1359-1364.

43. Olsson T, Bakhiet M, Edlund C, Hojeberg B, van der Meide PH, Kristensson K. Bidirectional activating signals between Trypanosoma brucei and CD8+ T cells: a trypanosome-released factor triggers interferon-gamma production that stimulates parasite growth. Eur J Immunol. 1991;21(10):2447-2454.

44. Gobert AP, Semballa S, Daulouede S, et al. Murine macrophage use oxygen- and nitric oxide-dependent mechanisms to synthesize S-nitroso-albumin and to kill extracellular trypanosomes. Infect Immun. 1998;66(9):4068-4072.

45. Hertz CJ, Filutowicz H, Mansfield JM. Resistance to the African trypanosomes is IFN-gamma dependent. J Immunol. 1998;161(12):6776-6783.

46. Namangala B, Noel W, De Baetselier P, Brys L, Beschin A. Relative contribution of interferon-gamma and interleukin-10 to resistance to murine African trypanosomosis. J Infect Dis. 2001;183(12):1794-1800.

47. Inoue $\mathrm{N}$, Inoue $\mathrm{M}$, Kuriki $\mathrm{K}$, et al. Interleukin 4 is a crucial cytokine in controlling Trypanosoma brucei gambiense infection in mice. Vet Parasitol. 1999;86(3):173-184.

48. Sileghem M, Darji A, Hamers R, Van de Winkel M, De Baetselier P. Dual role of macrophages in the suppression of interleukin 2 production and interleukin 2 receptor expression in trypanosome-infected mice. Eur J Immunol. 1989;19(5):829-835.

49. Schleifer KW, Filutowicz H, Schopf LR, Mansfield JM. Characterization of $\mathrm{T}$ helper cell responses to the trypanosome variant surface glycoprotein. J Immunol. 1993;150(7):2910-2919. 
50. Kaushik RS, Uzonna JE, Zhang Y, Gordon JR, Tabel H. Innate resistance to experimental African trypanosomiasis: differences in cytokine (TNF-alpha, IL-6, IL-10 and IL-12) production by bone marrowderived macrophages from resistant and susceptible mice. Cytokine. 2000;12(7):1024-1034.

51. Pan W, Ogunremi O, Wei G, Shi M, Tabel H. CR3 (CD11b/CD18) is the major macrophage receptor for IgM antibody-mediated phagocytosis of African trypanosomes: diverse effect on subsequent synthesis of tumor necrosis factor alpha and nitric oxide. Microbes Infect. 2006;8:1209-1218.

52. Blum ML, Down JA, Gurnett AM, Carrington M, Turner MJ, Wiley DC. A structural motif in the variant surface glycoproteins of Trypanosoma brucei. Nature. 1993;362(6421):603-609.

53. Lança AS, De Sousa KP, Atouguia J, Prazeres DM, Monteiro GA, Silva MS. Trypanosoma brucei: immunisation with plasmid DNA encoding invariant surface glycoprotein gene is able to induce partial protection in experimental African trypanosomiasis. Exp Parasitol. 2011;127(1):18-24.

54. Berriman M, Ghedin E, Hertz C, et al. The genome of the African trypanosome Trypanosoma brucei. Science. 2005;309(5733):416-422.

55. Paulnock DM, Coller SP. Analysis of macrophage activation in African trypanosomiasis. J Leuk Biol. 2001;69(5):685-690.

56. Hamadien M, Bakhiet M, Harris RA. Interferon-gamma induces secretion of trypanosome lymphocyte triggering factor via tyrosine protein kinases. Parasitology. 2000;120(3):281-287.
57. Nishimura K, Hamashita K, Okamoto Y, et al. Differential effects of interferon-gamma on production of trypanosome-derived lymphocytetriggering factor by Trypanosoma brucei gambiense and Trypanosoma brucei brucei. J Parasitol. 2004;90(4):740-745.

58. Hamadien M, Lycke N, Bakhiet M. Induction of the trypanosome lymphocyte-triggering factor (TLTF) and neutralizing antibodies to the TLTF in experimental African trypanosomiasis. Immunology. 1999;96(4):606-611.

59. Sacks D, Sher A. Evasion of innate immunity by parasitic protozoa. Nat Immunol. 2002;3(11):1041-1047.

60. Namangala B, de Baetselier P, Brijs L, et al. Attenuation of Trypanosoma brucei is associated with reduced immunosuppression and concomitant production of Th2 lymphokines. J Infect Dis. 2000;181(3):1110-1120.

61. Sternberg JM, Rodgers J, Bradley B, Maclean L, Murray M, Kennedy PG. Meningoencephalitic African trypanosomiasis: brain IL-10 and IL-6 are associated with protection from neuro-inflammatory pathology. J Neuroimmunol. 2005;167(1-2):81-89.

62. Namangala B, De Baetselier P, Noel W, Brys L, Beschin A. Alternative versus classical macrophage activation during experimental African trypanosomosis. J Leuk Biol. 2001;69:387-396.

\section{Publish your work in this journal}

The International Journal of Interferon, Cytokine and Mediator Research is an international, peer-reviewed, open-access, online journal. The focus of the journal is to publish original research, reports, editorials, reviews and commentaries on all aspects of interferon, cytokine and mediators of inflammation from labora- tory science to therapeutic indications and clinical studies. The manuscript management system is completely online and includes a very quick and fair peer-review system, which is all easy to use. Visit http://www.dovepress.com/testimonials.php to read real quotes from published authors. 